\title{
EFFECTS OF N-3 POLYUNSATURATED FATTY ACIDS ON LEFT VENTRICULAR FUNCTION AND CORONARY FLOW IN CHILDREN WITH TYPE 1 DIABETES MELLITUS
}

\author{
E.H. Aburawi ${ }^{1}$, P. Liuba ${ }^{2}$, M. Odermarsky ${ }^{2}$, S. Sjöblad ${ }^{2}$, E. Pesonen ${ }^{2}$ \\ ${ }^{I}$ Paediatrics, United Arab Emirates University, Faculty of Medicine and Health Sciences, Al-Ain, United \\ Arab Emirates, ${ }^{2}$ Paediatrics, Skane University Hospital, Lund University, Lund, Sweden
}

Purposes: Dietary supplementation with N-3 Polyunsaturated Fatty Acids (n-3 PUFAs) could have beneficial effects on cardiovascular system in patients with type 1 diabetes mellitus (DM1).

Methods: In a double-blind placebo controlled crossover study, 33 children with DM1 duration of more than one year were randomly and equally assigned to either n-3 PUFAs (2 gm/day, Nycoplus ${ }^{\circledR}$ Omega-3, 1000 $\mathrm{mg}$ ) or placebo treatment for 8 weeks. Following a 4-week period recovery, the groups were crossovered with above treatments for another 8 weeks. Transthoracic Doppler echocardiography (TTDE) study was done on pre and post treatment visits, and after one month's treatment free recovery for left ventricular function and flow in the left anterior descending coronary artery (LAD).

Results: Of recruited children 28 (85\%) completed the study. n-3 PUFAs treatment was associated with increase in mean cardiac index (CI; from $2.7 \pm 0.4$ to $3.7 \pm 0.81 / \mathrm{min} / \mathrm{m}^{2}, \mathrm{p}<0.0001$ ) and left ventricular fractional shortening (FS; from $31 \pm 2.5$ to $39 \pm 3 \%, \mathrm{p}<0.0001$ ). The treatment decreased both LAD peak flow velocity (PFVd) from $96 \pm 17$ to $68 \pm 12 \mathrm{~cm} / \mathrm{s}, \mathrm{p}<0.0001$ and $\mathrm{LAD} C \mathrm{CF}$ from $105 \pm 31$ to $66 \pm 15 \mathrm{ml} / \mathrm{min}, \mathrm{p}<$ 0.0001 ). One month after stopping the treatment CI decreased from $3.7 \pm 0.8$ to $2.6 \pm 0.5 \mathrm{l} / \mathrm{min} / \mathrm{m}^{2}, \mathrm{p}<0.0001$ and mean FS from $39 \pm 3$ to $32 \pm 2, \mathrm{p}<0.0001$. Mean PFVd increased from $68 \pm 12$ to $90 \pm 12 \mathrm{~cm} / \mathrm{s}, \mathrm{p}<0.0001$ and $\mathrm{CF}$ from $66 \pm 15$ to $108 \pm 30 \mathrm{ml} / \mathrm{min}, \mathrm{p}<0.0001$.

Conclusions: In patients with DM1 n-3 PUFA therapy increased cardiac index and LV systolic function. The basal coronary flow decrease improving the circumstances for better coronary flow reserve. 